\title{
Modulated Model Predictive Direct Power Control of DFIM Considering Magnetic Saturation Effects
}

\author{
Shafiq Odhano, Pericle Zanchetta \\ Department of Electrical and Electronic Engineering \\ The University of Nottingham \\ Nottingham, United Kingdom
}

\author{
Sandro Rubino, Radu Bojoi \\ Department of Energy \\ Politecnico di Torino \\ Turin, Italy
}

\begin{abstract}
In this paper, an optimal voltage vector based model predictive control strategy is investigated for the direct power control of a doubly fed induction machine. The model predictive control computes optimal voltage vector that minimizes the error in active and reactive power. The computed voltage vector, if within the linear regulation range, is passed onto a modulator to be applied in the next sampling instant. In the over-modulation range the voltage vector is linearly scaled down, before modulation, to maintain optimality. The paper also focuses on the saturation of main flux inside an induction machine and its impact on reactive power control when stator current sensors are not installed. The machine's saturation characteristic is fully utilized to realize full-state stator flux observer that is used to estimate stator currents which give accurate prediction of reactive power. Consequently, stator current sensors can be excluded. Simulations and experimental analyses are conducted on a test machine to verify fast dynamics of predictive control and the estimation accuracy of stator current.
\end{abstract}

Index Terms - direct power control, doubly fed induction machine, magnetic saturation, modulated model predictive control

\section{INTRODUCTION}

Wound rotor induction machines are commonly used as motors in high torque applications [1]. As generators they are employed in wind energy conversion systems coupled with variable speed wind turbines. They allow to downsize the power electronic converter required for four-quadrant active and reactive power control. The direct power control of a doubly fed induction machine (DFIM) is widely researched [2]-[7] in the literature.

Direct power control is usually achieved the same way [2] as direct torque and flux control of an induction machine, however this leads to a non-constant converter switching frequency. Model predictive control (MPC) in its canonical finite control set (FCS) implementation also results in a variable switching frequency [8], [9], however, some authors have reported the application of prediction-based control with constant switching frequency [4]-[6] that uses a modulator.

In [8], a model predictive control scheme that achieves active and reactive power control under unbalanced grid conditions is presented. The harmonics contained in the grid voltage pollute the active and reactive power references which are removed (compensated) and the resultant power references ensure sinusoidal currents being injected into the grid from the DFIM as well as reduced torque ripple on the generator shaft. It has been noted that the power compensation terms are necessary also when switching table based direct power control is used. A robust FCS-MPC is proposed in [9] where a voltage correction term is added to reference rotor voltage to account for parameter errors. The reference voltage, generated by current control, has two components: first arising from current prediction equations and the second term is introduced to eliminate error due to parameter mismatch. The cost function compares the total reference voltage with the six inverter states and the algorithm selects the state that minimizes the error in rotor-side voltage. In these works [8], [9], however, the switching frequency is not constant. A similar work is presented in [7] where the phase locked loop (PLL) is excluded for its vulnerability to grid harmonics which appear in angle estimation. A second-order vector integration is employed as direct resonant controller to remove fifth and seventh harmonics to render the currents as smooth sinusoids and minimize ripples in power and consequently in shaft torque. To account for varying grid frequency, an adaptive frequency detection scheme is also included to track the fundamental grid frequency component. The power control is achieved through proportional-integral regulators. It has been shown that, compared to a PLL based approach, this scheme is robust and stable against harmonic distortions in the grid voltage.

An algorithm presented in [4] predicts the stator active and reactive power and computes the voltage command to be applied at the next sampling instant. The errors with respect to reference power values are eliminated by applying voltage vectors computed through the inversion of the machine differential equations. This makes the scheme resemble the classical deadbeat control. As the computed reference voltage is to be applied through a modulator, the method produces constant switching frequency. A similar scheme is developed in [5] in which virtual torque control is proposed for grid synchronization purposes. However, the control of active and reactive power follows the same principle as of [4] and therefore the strategy is close to deadbeat control. This scheme is combined with a rotor position sensorless control. Another direct power control technique with fixed switching frequency and under unbalanced grid conditions is investigated in [6]. Here the stator active and reactive power slopes are estimated based on different inverter switching voltage vectors and four vectors that have positive durations, and that minimize a cost 
function of power errors, are applied to achieve power control. Of the four selected vectors two are the zero vectors V0 and V7 while the other two are the active vectors given by the sector in which the flux vector lies. The computation of duty cycles of each active and zero vector based on active and reactive power slopes makes the control technique similar to modulated MPC [10]. The performance of the proposed technique is analysed, in simulation, under unbalanced grid voltage conditions. A DFIM model predictive control for rotor side converter with inductive-capacitive output filter is presented in [11]. An analytical solution with integral error feedback is proposed for current control.

Apart from prediction-based direct power control, the research also focuses on other control techniques such as a sliding mode controller [3]. An extended active power concept is introduced to account for harmonics, caused by grid unbalances, appearing in power references. The negative sequence components of grid voltage and current appear in the extended active power which are compensated in feed-forward manner to extract power from DFIM that consists only of the fundamental positive sequence components of voltage and current. The control is implemented through the integral form sliding surface variant of sliding mode controller to achieve suitable steady state and transient performances. While [2][9], [11] use two-level voltage source inverter (VSI), [12] has demonstrated the vector control of a DFIM using indirect matrix converter with changing dc-link voltage. Although the power control is obtained through traditional proportionalintegral current regulators, it has been concluded that a highperformance power control is possible also without bulky dc-link capacitors used in a VSI.

In almost all the direct power control strategies cited above, the machine parameters are considered as known constants. Although it is true for stator and rotor resistances (as long as temperature does not change) and leakage inductances, the magnetizing inductance does vary with main flux saturation as for any induction machine. In [13] the variation of magnetizing inductance is highlighted and a model reference adaptive system is used to track its changes. The accurate value of magnetizing inductance used in control is stated to help improve robustness of the control especially when rotor position sensor is excluded to implement sensorless control. The short-circuit modelling of a DFIM presented in [14] describes how the main flux saturation affects the controllability of the machine especially when uninterrupted control under fault conditions is needed. Apart from [13], [14], the influence of magnetic saturation on the effectiveness of direct power control is not very widely reported in the literature.

This paper, therefore, presents an in-depth analysis of how a detuned magnetizing inductance influences the accuracy of power estimation, especially the reactive power, when the stator current sensors are not present. The machine under study is first tested to define its magnetizing characteristic which is then used to compute the instantaneous value of magnetizing inductance through look-up tables. A full-state flux observer is also designed that (i) takes magnetic saturation into account,

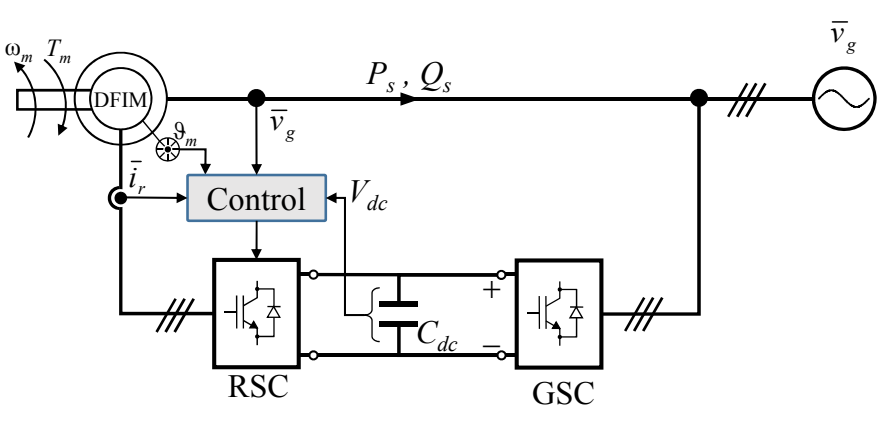

Fig. 1. Doubly-fed induction machine connection to the grid.

(ii) helps estimate the stator currents, and (iii) eliminates the need for a PLL to track grid voltage (or stator flux) vector position. The direct power control is achieved through an optimal voltage vector based modulated model predictive control that optimizes the voltage vector to be applied both in linear voltage regulation range as well as in over-modulation. Simulation and experimental results are presented to show that the control achieves fast dynamic performance, even when the rotor side converters dc-link voltage is limited. It has been demonstrated that almost null steady state error in active and reactive power control can be achieved even without measuring stator current.

The following sections briefly describe the modelling of a DFIM (section II) and the flux observer (section III) that does not need stator current measurement. In section IV the modulated MPC strategy used in this paper is detailed and section $\mathrm{V}$ presents simulation and experimental results. Section VI concludes the paper.

\section{Modelling of DFIM for Direct Power Control}

Like a squirrel cage induction machine, a DFIM consists of a distributed stator winding, but unlike a squirrel cage machine, the rotor of a DFIM also contains windings. These windings are connected to external circuit through slip rings. Fig. 1 shows a generalized scheme of DFIM connection to the grid. GSC stands for grid side converter and RSC for rotor side converter. The control of GSC is not discussed in this paper, the focus is on RSC control. It can be noticed that the stator current is not considered as a measured quantity.

\section{A. Stator and rotor voltage equations}

While writing the following equations, reference is made to Fig. 2 in which the reference frames are defined. The stator stationary reference frame $\alpha_{s} \beta_{s}$ has its $\alpha$-axis aligned to phase ' $a$ ' of the stator winding. The reference frame $\alpha_{r} \beta_{r}$ is fixed with respect to the rotor windings and rotates at rotor angular speed $\omega_{r}$ (not shown in Fig. 2). The power control will be carried out in stator flux oriented (SFO) $d_{s} q_{s}$ frame [15]. The stator and rotor voltage equations of a DFIM in stator fluxoriented (SFO) $d_{s} q_{s}$ reference frame (defined in Fig. 2) can be written as: 


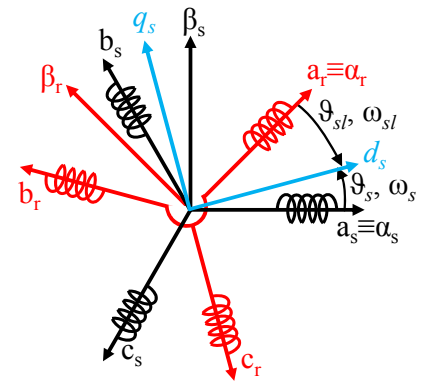

Fig. 2. DFIM reference frames definition.

$$
\begin{gathered}
\bar{v}_{s}=R_{s} \bar{i}_{s}+\frac{d \bar{\lambda}_{s}}{d t}+j \omega_{s} \bar{\lambda}_{s} \\
\bar{v}_{r}=R_{r} \bar{i}_{r}+\frac{d \bar{\lambda}_{r}}{d t}+j \omega_{s l} \bar{\lambda}_{r}
\end{gathered}
$$

where $\bar{v}, \bar{i}, \bar{\lambda}$ are voltage, current and flux vectors, respectively, with subscript 's' denoting stator quantities and ' $r$ ' stands for rotor. $R_{s}$ and $R_{r}$ are the stator and rotor resistance, respectively. $\omega_{s}$ is stator electrical frequency (in $\mathrm{rad} / \mathrm{s}$ ), $\omega_{s l}$ is the slip frequency (in $\mathrm{rad} / \mathrm{s}$ ) and $j$ is the complex operator. The stator and rotor fluxes are related to respective currents through the following relations:

$$
\begin{aligned}
& \bar{\lambda}_{s}=L_{s} \bar{i}_{s}+L_{m} \bar{i}_{r} \\
& \bar{\lambda}_{r}=L_{m} \bar{i}_{s}+L_{r} \bar{i}_{r}
\end{aligned}
$$

where $L_{s}, L_{r}$ and $L_{m}$ are stator, rotor and magnetizing inductance, respectively. It must be noted that (3) and (4) are valid in all reference frames of Fig. 2, namely stator $\alpha_{s} \beta_{s}$, rotor $\alpha_{r} \beta_{r}$ and SFO $d_{s} q_{s}$ frames.

Noting that the stator current $\bar{i}_{s}$ is not a measured quantity, it can be eliminated from rotor flux equation by substituting (3) into (4) to get:

$$
\bar{\lambda}_{r}=\sigma L_{r} \bar{i}_{r}+k_{s} \bar{\lambda}_{s}
$$

here $\sigma$ is the leakage factor defined as $1-L_{m}^{2} / L_{s} / L_{r}$ and $k_{s}$ is the stator coupling factor given by $L_{m} / L_{s}$. Substituting (5) into (2) and rearranging to obtain the rotor current state equation:

$$
\frac{d \bar{i}_{r}}{d t}=-\frac{R_{r}}{\sigma L_{r}} \bar{i}_{r}-j \omega_{s l} \bar{i}_{r}-\frac{j \omega_{s l} k_{s}}{\sigma L_{r}} \bar{\lambda}_{s}+\frac{\bar{v}_{r}}{\sigma L_{r}}
$$

\section{B. Active and reactive power}

The stator active and reactive power in terms of stator $d q$ currents and voltages is given by:

$$
\begin{array}{r}
P_{s}=\frac{3}{2}\left(v_{d s} i_{d s}+v_{q s} i_{q s}\right) \\
Q_{s}=\frac{3}{2}\left(v_{q s} i_{d s}-v_{d s} i_{q s}\right)
\end{array}
$$

Since the active and reactive power control is achieved through rotor side, the stator currents in (7) and (8) can be replaced with rotor currents using (3).

$$
\bar{i}_{s}=\frac{\bar{\lambda}_{s}-L_{m} \bar{i}_{r}}{L_{s}}
$$

From the definition of SFO frame (of Fig. 2), it is noted that $\lambda_{d s}=\left|\bar{\lambda}_{s}\right|$ and $\lambda_{q s}=0$. From (1), in steady state, the stator voltage is given by (10).

$$
\bar{V}_{s}=R_{s} \bar{I}_{s}+j \omega_{s} \bar{\Lambda}_{s}
$$

If $R_{S} \bar{I}_{s} \ll \omega_{s} \bar{\Lambda}_{s}$, then the stator voltage's $d q$ components can be approximated as: $v_{q s} \approx\left|\bar{v}_{g}\right|$ and $v_{d s} \approx 0$, where $\bar{v}_{g}$ is the instantaneous grid voltage vector. Thus, after substituting (9) into (7) and (8), the stator active and reactive power in terms of grid voltage vector and rotor currents will be:

$$
\begin{gathered}
P_{s}=-\frac{3}{2} k_{s}\left|\bar{v}_{g}\right| i_{q r} \\
Q_{s}=\frac{3}{2}\left|\bar{v}_{g}\right|\left(\frac{\left|\bar{\lambda}_{s}\right|}{L_{s}}-k_{s} i_{d r}\right)
\end{gathered}
$$

Taking the time derivative of (11) and (12) while noting that $\left|\bar{v}_{g}\right|=$ const. and $\left|\bar{\lambda}_{s}\right|=$ const . and substituting (6), the active and reactive power state equations become:

$$
\begin{gathered}
\frac{d P_{s}}{d t}=\frac{3}{2} k_{s}\left|\bar{v}_{g}\right|\left(\frac{R_{r}}{\sigma L_{r}} i_{q r}+\omega_{s l} i_{d r}+\frac{\omega_{s l} k_{s}}{\sigma L_{r}}\left|\bar{\lambda}_{s}\right|-\frac{v_{q r}}{\sigma L_{r}}\right) \\
\frac{d Q_{s}}{d t}=\frac{3}{2} k_{s}\left|\bar{v}_{g}\right|\left(\frac{R_{r}}{\sigma L_{r}} i_{d r}-\omega_{s l} i_{q r}-\frac{v_{d r}}{\sigma L_{r}}\right)
\end{gathered}
$$

\section{FluX ObSERVER AND FiELd ORIENTATION}

In order to get the measured quantities in SFO frame of Fig. 2, a PLL is generally used [9]. In this work, the fullstate flux observer of an induction machine is exploited for field orientation. The flux-observer is constructed based on the stator and rotor voltage equations in respective stationary frames by setting $\omega_{s}=0$ and $\omega_{s l}=0$ in (1) and (2), respectively. The stator flux from the rotor and stator voltage equations (eliminating the stator current) is given in (15) and (16), respectively, where superscripts ' $r e$ ' and 'se' stand for rotor equation and stator equation, respectively. In (16), $\tau_{s}$ represents stator time constant defined as $L_{S} / R_{s}$. It must be noted that $\bar{i}_{r}$ in (16) is the rotor current transformed to stator stationary frame $\alpha_{s} \beta_{s}$ of Fig. 2 through rotor mechanical angle $\theta_{m}$.

$$
\begin{gathered}
\bar{\lambda}_{s}^{r e}=\frac{1}{k_{r}}\left\{\int\left(\bar{v}_{r}-R_{r} \bar{i}_{r}\right) d t-\sigma L_{r} \bar{i}_{r}\right\} \\
\bar{\lambda}_{s}^{s e}=\frac{1}{\tau_{s}}\left\{\int\left(-\bar{\lambda}_{s}+\tau_{s} \bar{v}_{s}+L_{m} \bar{i}_{r}\right) d t\right\}
\end{gathered}
$$

A flux-observer is constructed by combining (15) and (16) through an observer gain $g$ as shown in Fig. 3. This observer has the benefits of no open-loop integration as opposed to an observer based only on stator equation. To further mitigate the effects of dc-offset arising from grid voltage sensors, the pure integration of (16) is replaced with the scheme of [16]. In Fig. 3, the parameters such as $L_{m}$ and $\tau_{s}$ are shown as functions of $\lambda_{m}$ to appropriately consider their dependence on the saturation characteristic of the machine. Still in Fig. 3, $\Delta_{a b c}$ represents the duty cycle vector of RSC switches, $v_{d c}$ is the measured dc-link voltage and 'DT' stands for deadtime compensation look-up tables [17]. The inverter voltage error as a function of current $\left(\bar{v}_{\alpha \beta}^{d t}\right)$ is subtracted from the applied voltage to obtain accurate rotor induced voltage for flux-observer. 
The sine and cosine functions of stator flux angle are obtained directly from the $\alpha$ and $\beta$ components of the observed flux as (17). The use of the flux-observer along with dcoffset elimination scheme [16] and inverter error compensation allows to replace the PLL altogether.

$$
\cos \hat{\theta}_{s}=\frac{\hat{\lambda}_{\alpha}}{\left|\hat{\bar{\lambda}}_{s}\right|} \quad \sin \hat{\theta}_{s}=\frac{\hat{\lambda}_{\beta}}{\left|\hat{\bar{\lambda}}_{s}\right|}
$$

The other advantage of using the flux-observer of Fig. 3 is realized in terms of accurate stator current estimation that helps exclude the stator current sensors. The magnetizing characteristic of the machine is utilized to track online the change in magnetizing inductance $L_{m}$ and, consequently, $\tau_{s}$ that gives accurate stator and rotor flux estimation from which the magnetizing flux-linkage $\bar{\lambda}_{m}$ is obtained using (18) that, in turn, gives estimated stator current through (19). In (18), $L_{l r}$ denotes rotor leakage inductance.

$$
\begin{gathered}
\hat{\bar{\lambda}}_{m}=\hat{\bar{\lambda}}_{r}-L_{l r} \bar{i}_{r} \\
\tilde{\bar{i}}_{s}=\frac{\hat{\bar{\lambda}}_{m}}{L_{m}\left(\left|\hat{\bar{\lambda}}_{m}\right|\right)}-\bar{i}_{r}
\end{gathered}
$$

\section{Modulated Model Predictive Control}

In FCS-MPC, following a cost function minimization one of the seven possible inverter states are selected as optimal [18]. The selected inverter state is applied for a complete switching period. The FCS-MPC produces a variable switching frequency and gives higher ripple in controlled variables. In this paper, a modulated alternative of MPC is used based on [19], [20]. The application of any MPC scheme requires prediction of state variables. For this, the rotor current state equation (6) and the active and reactive power state equations (13) and (14) are discretized using Euler's approximation as follows, where $k$ denotes current sampling instant and $k+1$ the next and $T_{s}$ is the sampling time. Even though the grid voltage $\bar{v}_{g}$, the stator flux $\bar{\lambda}_{s}$ and the slip frequency $\omega_{s l}$ do not vary much over one sampling interval, they are written with sampling instant markers $k, k-1$ for correctness.

$$
\begin{array}{r}
\bar{i}_{r}(k)=\left(1-\frac{R_{r} T_{s}}{\sigma L_{r}}\right) \bar{i}_{r}(k-1)-j \omega_{s l}(k-1) T_{s} \bar{i}_{r}(k-1) \\
-\frac{j \omega_{s l}(k-1) k_{s}}{\sigma L_{r}} T_{s} \bar{\lambda}_{s}(k-1)+\frac{T_{s}}{\sigma L_{r}} \bar{v}_{r}(k-1) \\
P_{s}(k+1)=P_{s}(k)+\frac{3}{2} T_{s} k_{s}\left|\bar{v}_{g}(k)\right|\left\{\frac{R_{r}}{\sigma L_{r}} i_{q r}(k)\right. \\
\left.+\omega_{s l}(k) i_{d r}(k)+\frac{\omega_{s l}(k) k_{s}}{\sigma L_{r}}\left|\bar{\lambda}_{s}(k)\right|-\frac{v_{q r}(k)}{\sigma L_{r}}\right\} \\
Q_{s}(k+1)=Q_{s}(k)+\frac{3}{2} T_{s} k_{s}\left|\bar{v}_{g}(k)\right|\left\{\frac{R_{r}}{\sigma L_{r}} i_{d r}(k)\right. \\
\left.-\omega_{s l}(k) i_{q r}(k)-\frac{v_{d r}(k)}{\sigma L_{r}}\right\}
\end{array}
$$

The control algorithm proceeds in the following sequence:

- The grid voltage $\bar{v}_{g}$ and rotor current $\bar{i}_{r}$ are read in stator and rotor reference frames, respectively. The rotor mechanical position is acquired from the rotor position sensor.

- The flux-observer of Fig. 3 estimates the stator flux $\left(\bar{\lambda}_{s}\right)$ and gives the sine and cosine of stator flux angle.

- The measured stator voltages and rotor currents are transformed to $d_{s} q_{s}$-frame.

- The rotor current vector is predicted using (20) based on the measurements and the applied rotor voltage $\bar{v}_{r}$ at previous sampling instant (after removing the inverter dead-time effects for accurate prediction).

- The stator active and reactive power at the current sampling instant is obtained using (11) and (12).

- To obtain predictions for the next sampling instant, every inverter switching state is evaluated. The voltage vector in rotor $\alpha_{r} \beta_{r}$ frame is given by (23) for different switching states.

$$
\bar{v}_{\alpha \beta r}=\frac{2}{3} v_{d c}\left[\begin{array}{lll}
1 & e^{j \frac{2 \pi}{3}} & e^{j \frac{-2 \pi}{3}}
\end{array}\right]\left[\begin{array}{l}
S_{a} \\
S_{b} \\
S_{c}
\end{array}\right]
$$

where $S$ denotes switching function with subscripts ' $a$ ', ' $b$ ', and ' $c$ ' representing phases. The top switch of the inverter leg is closed for $S=1$.

- The voltage vector of (23) is converted to SFO $d q$-frame for each of the seven inverter states and the active and reactive power for the next sampling instant are predicted through (21) and (22).

- An error vector is computed based on the reference values of active and reactive power as:

$$
\bar{e}_{i}=\left(P_{s}^{*}-P_{s}(k+1)\right)+j\left(Q_{s}^{*}-Q_{s}(k+1)\right)
$$

where the subscript ' $i$ ' denotes the inverter state $i \in[0,1, \ldots, 6]$ with $\bar{e}_{0}$ denoting the error when zero vector is applied.

- The two inverter states that are adjacent and that give minimum magnitude of the error vector (24) are identified [20].

- The following system of linear equations is solved to compute the duty cycle $d_{1}$ and $d_{2}$ of each of the two vectors identified in the previous step [19].

$$
\left[\begin{array}{ll}
e_{1 P}-e_{0 P} & e_{2 P}-e_{0 P} \\
e_{1 Q}-e_{0 Q} & e_{2 Q}-e_{0 Q}
\end{array}\right]\left[\begin{array}{l}
d_{1} \\
d_{2}
\end{array}\right]=\left[\begin{array}{l}
-e_{0 P} \\
-e_{0 Q}
\end{array}\right]
$$

Here, the subscripts ' $P$ ' and ' $Q$ ' denote the real and imaginary parts of the error vector $\bar{e}_{i}$, respectively.

- When the target active $\left(P_{s}^{*}\right)$ and reactive $\left(Q_{s}^{*}\right)$ power is achievable in one switching period, the duty cycles given by (25) satisfy $d_{1}+d_{2} \leq 1$ and the duty cycle for zero vector is obtained as $d_{0}=1-d_{1}-d_{2}$. This is the linear regulation regime.

- The over-modulation region is encountered when the target active and reactive power cannot be reached in one switching period. In that case the solution of (25) produces the condition $d_{1}+d_{2}>1$. In order to maintain 


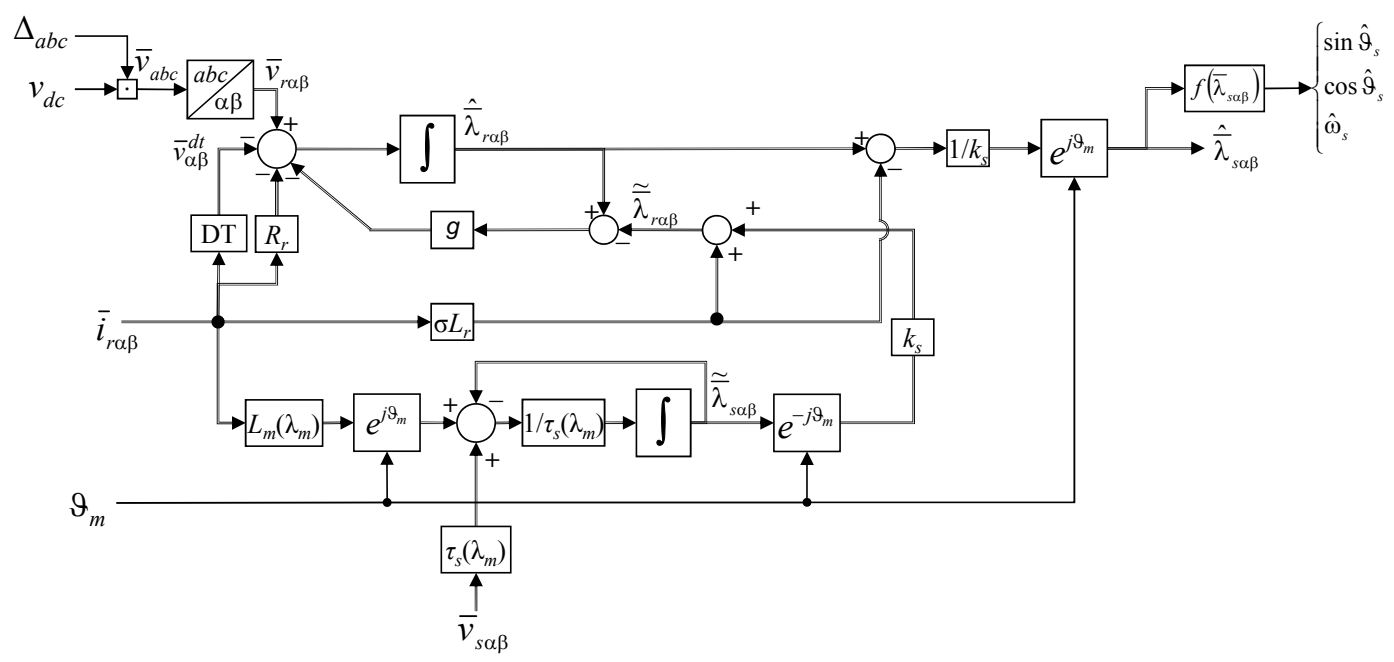

Fig. 3. Stator flux observer for DFIM.

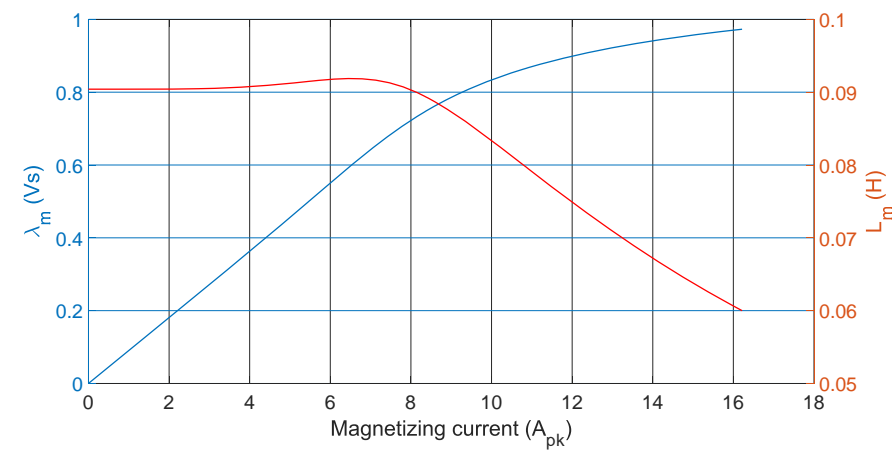

Fig. 4. Mutual flux-linkage (blue) and main inductance (red) as a function of magnetizing current.

optimality also in case of over-modulation, the duty cycles are linearly scaled down as:

$$
d_{1}=\frac{d_{1}}{d_{1}+d_{2}}, \quad d_{2}=1-d_{1}, \quad d_{0}=0
$$

\section{Results AND Discussion}

The validation of the direct power control strategy through modulated MPC is carried out on a commercial $7.5 \mathrm{~kW}$ wound rotor induction machine with its rotor windings accessible through slip rings. The machine under test is first subjected to no-load and short-circuit tests following the IEEE guidelines as outlined in [21]. The machine's magnetizing characteristic is obtained from the data of no-load tests and is reported in Fig. 4. The figure shows the flux and magnetizing inductance as function of magnetizing current. It can be observed that in deep saturation, the magnetizing inductance reduces by about a third which has major implications on reactive power estimation using (12) if stator currents are not measured. Other equivalent circuit parameters identified for the test machine are: $R_{s}=0.41 \Omega, R_{r}=0.31 \Omega, L_{l s}=L_{l r}=5.7 \mathrm{mH}$.

\section{A. Simulation results}

For carrying out simulations, the data of Fig. 4 is used as a look-up table (LUT) to create a non-linear model of the DFIM in Matlab Simulink. The same LUT is used to estimate $L_{m}$ at various operating points of the machine. The estimated $L_{m}$ is used in the flux observer of Fig. 3 to get accurate flux vector magnitude.

To verify the dynamic performance of the optimal voltage vector based MPC proposed here, a step reference change in active and reactive power is applied while the machine is rotated through an external prime mover that maintains constant speed. Fig. 5 shows the dynamic response for active power change and Fig. 6 gives the controller performance on reactive power axis. The dc-link voltage of RSC is deliberately kept low (around $25 \mathrm{~V}$ ) to test the algorithm in over-modulation range. The duty cycles shown in the lower plots of Fig. 5 and Fig. 6 show saturated outputs for initial instants according to (26), notice the duty cycle for $d_{0}$. However, as soon as the errors are eliminable within one switching instant, the duty cycles are modulated as per (25). In these results, the saturation effects are not enabled as they are meant to test the control dynamics.

Fig. 7 presents results when the magnetic saturation effects are enabled. The reactive power is varied as a ramp to show its influence on magnetizing inductance. The top plot shows the reference and measured reactive power (and their difference as error) and the bottom plot gives the magnetizing inductance variations obtained from the LUT of Fig. 4. Fig. 8 presents the active and reactive power estimation errors when the saturation effects are enabled in the machine model but are not considered in the control and for the flux observer. The estimation errors are computed as the difference between actual stator powers (computed using the measured stator currents) and their estimates obtained through (11) and (12). As noted above and observed in Fig. 8, the impact of saturation on the estimation of active power is minimal. However, the 

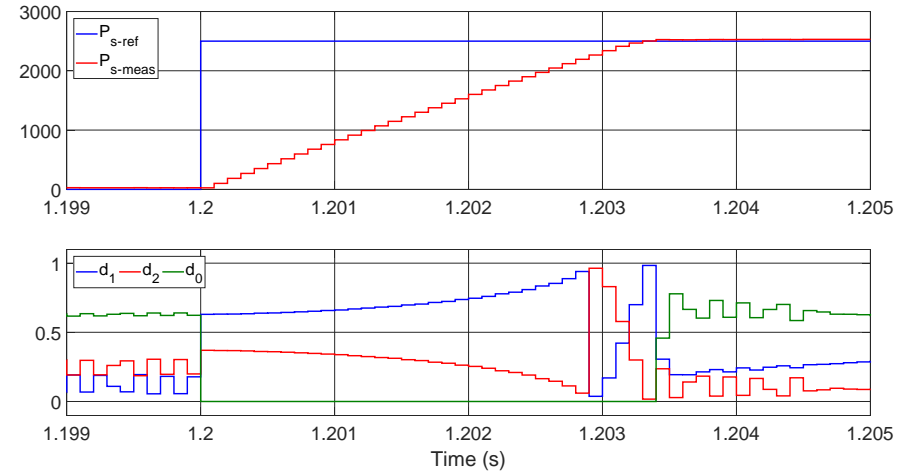

Fig. 5. Active power step response - top: reference and measured active power (W); bottom: duty cycles $d_{1}, d_{2}$, and $d_{0}$.
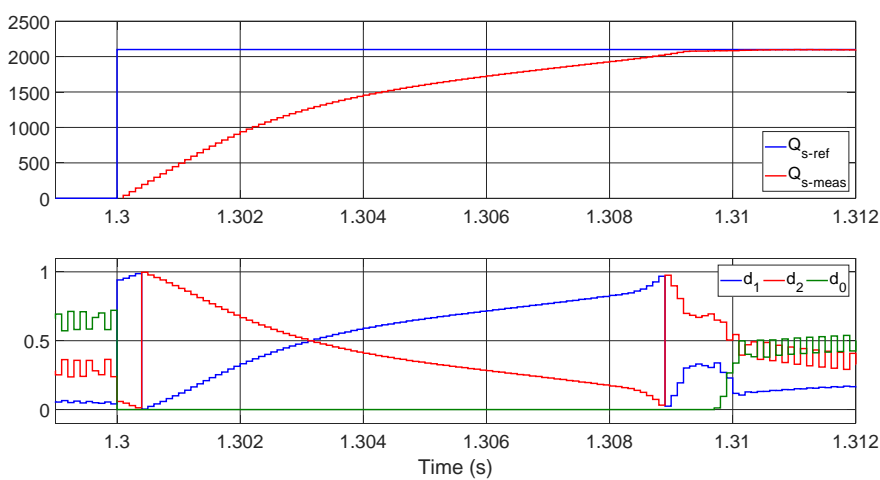

Fig. 6. Reactive power step response - top: reference and measured reactive power (VAr); bottom: duty cycles $d_{1}, d_{2}$, and $d_{0}$.
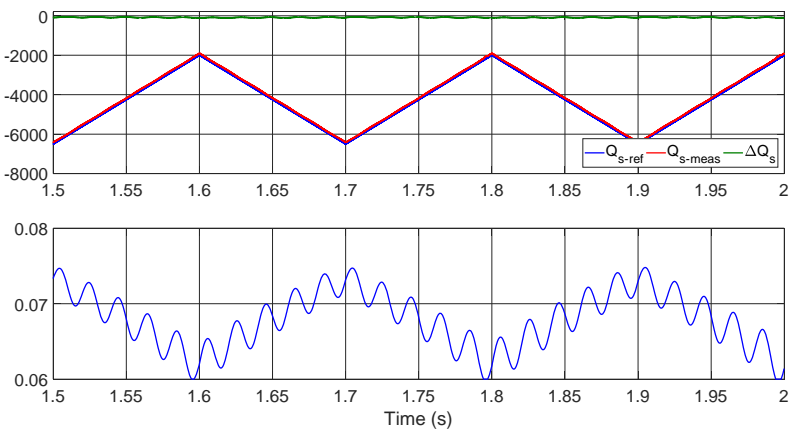

Fig. 7. Magnetizing inductance variations with reactive power - top: reference and measured reactive power and their error; bottom: magnetizing inductance in henrys.

estimation of reactive power is significantly improved when magnetic saturation effects are appropriately considered. Fig. 8 effectively demonstrates that open-loop reactive power control can be achieved with greater accuracy even without measuring stator currents.

\section{B. Experimental results}

Fig. 9 shows the photo of the test rig where the DFIM is coupled with a permanent-magnet machine that acts as a prime mover. The rotor position for the DFIM is obtained through a 25000 pulse per revolution incremental encoder. The stator
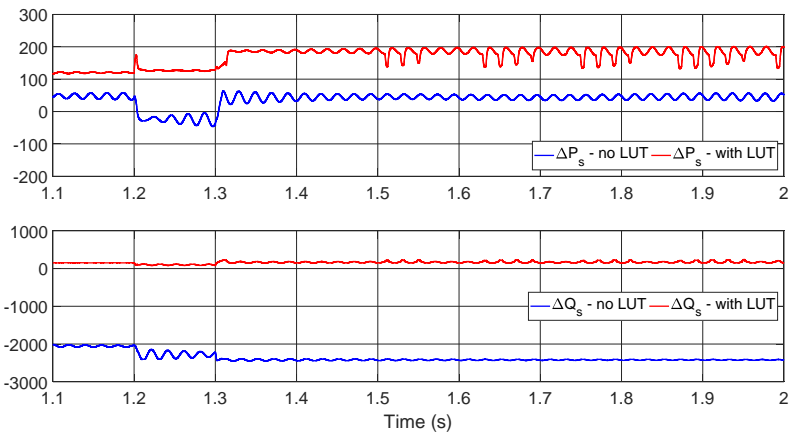

Fig. 8. Active (top) and reactive (bottom) power errors - blue: errors when magnetizing inductance is constant; red: when magnetizing inductance is obtained from LUT of Fig. 4.

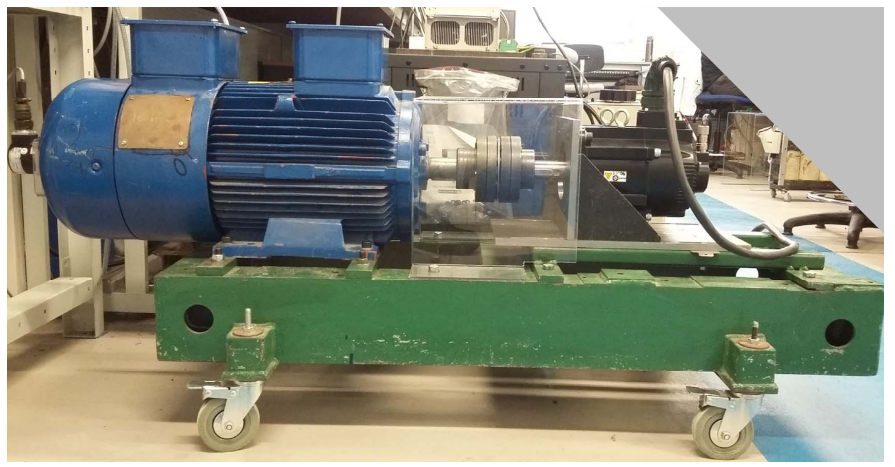

Fig. 9. Experimental setup - left: DFIM under test, right: prime mover.

voltage and current measurements are made available through appropriate voltage and current sensors. It must be noted that the stator current measurement is used only for verification purposes.

The RSC is a commercial $2 \mathrm{~kW}$ drive whose control board is replaced to allow direct access to the IGBT gate drivers. The control algorithm runs on a custom DSP/FPGA board that sends the switch duty cycle commands over a fibre-optic link. The switching frequency is $10 \mathrm{kHz}$. The shaft speed is maintained through the prime mover. The stator is connected to a $50 \mathrm{~Hz}$ grid.

1) Active and reactive power step response: Fig. 10 shows the results for an active power reference step of $2 \mathrm{~kW}$ when the shaft speed is maintained at $1540 \mathrm{rpm}$. The lower plot shows the rotor phase currents. It must be noted that the convention of consumer is used for the sign of power i.e. positive power is drawn from the grid and negative is injected into it. Fig. 11 gives the results for reactive power control. For this test, the shaft speed is reduced to $1500 \mathrm{rpm}$ such that no active power is produced/consumed. The stator no-load reactive power at rated flux is close to $5000 \mathrm{VAr}$ which is brought to $0 \mathrm{VAr}$ to effectuate unity power factor operation. The lower plot of the figure shows the $d$ - and $q$-axis stator currents. The stator $d$-axis current at no-load is the rated magnetizing current (cf. Fig. 4) which is compensated through the rotor circuit that results in unity power factor operation. The inset graphs in Fig. 10 and Fig. 11 show the zoomed-in results for control dynamics. It 

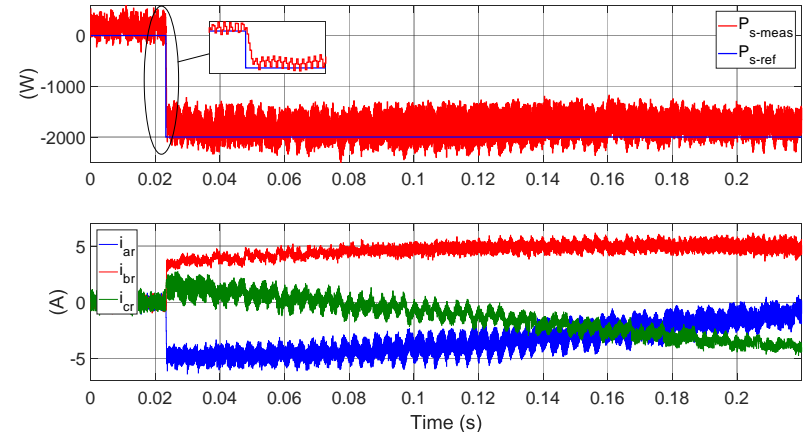

Fig. 10. Experimental results for active power step response - top: reference and measured active power, bottom: measured rotor phase currents.
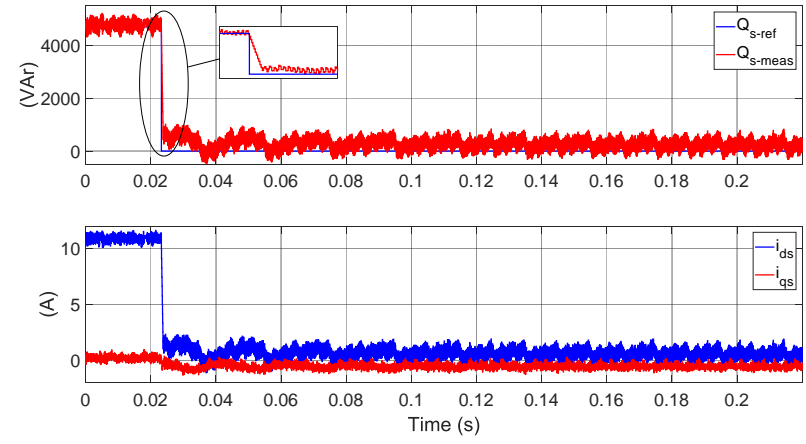

Fig. 11. Experimental results for reactive power step response - top: reference and measured reactive power, bottom: measured stator $d$-and $q$-axis currents.

must be noted that to obtain the results of Fig. 10 and Fig. 11, the measured stator current is used only to compute active and reactive power but the control and flux-observer do not include stator current measurement. Instead, the LUT (of Fig. 4) is used to correct $L_{m}$ online based on the observed mutual flux value.

Fig. 12 presents results for a step change in both active and reactive power at the same instant $\left(\omega_{m}=1540 \mathrm{rpm}\right)$. It can be observed that the control dynamics of Fig. 10 and Fig. 11 are preserved. The stator and rotor $d$ - and $q$-axis currents are also reported for completeness. Furthermore, to verify the operation in overmodulation region, an active power step of $6 \mathrm{~kW}(80 \%$ of rated machine power) is applied and the duty cycles given by (25) and (26) are shown in Fig. 13. The figure is zoomed in around the instant when the step is applied to show saturated operation for initial instants (notice that $\left.d_{0}=0\right)$ and the modulation once the target is achievable in one switching instant (now $d_{0} \neq 0$ ).

2) Saturation influence on reactive power: To demonstrate that in the absence of stator current measurement, the reactive power control is affected by whether the saturation characteristic (Fig. 4) is taken into account or not, the reactive power step of Fig. 11 is applied without LUT for $L_{m}$ correction. The results presented in Fig. 14 show that the reactive power control has a considerable steady-state error and the same is noted from the stator $d$-axis current (shown in the lower plot). All other conditions of Fig. 11 are kept the same for Fig. 14.
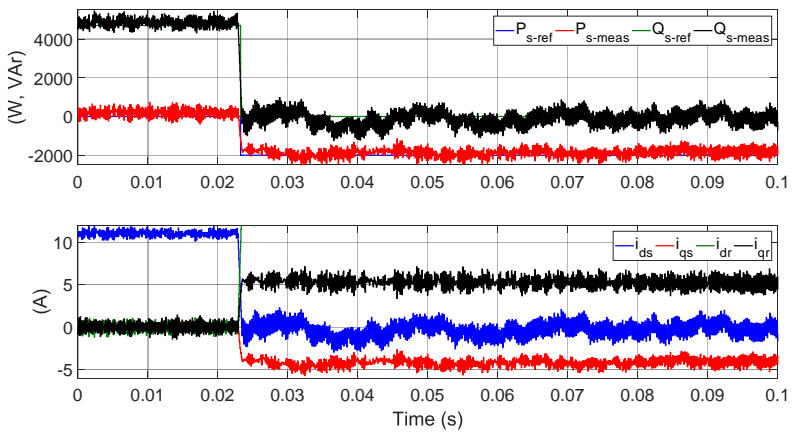

Fig. 12. Experimental results for active and reactive power step response top: reference and measured power, bottom: measured stator and rotor $d$ - and $q$-axis currents.
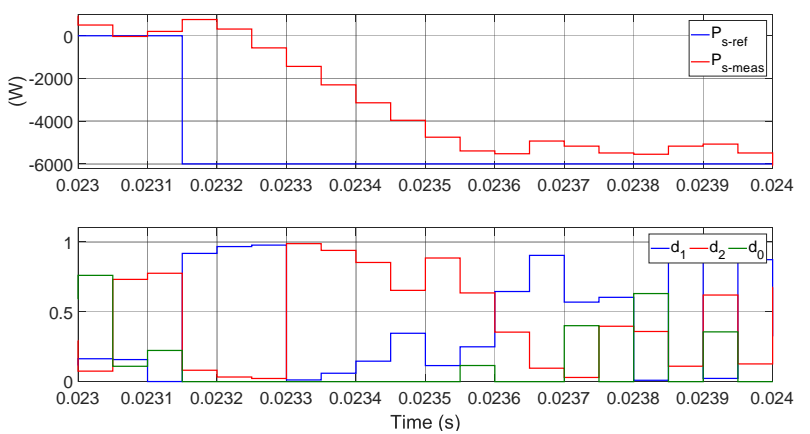

Fig. 13. Experimental results for active power step for overmodulation - top: reference and measured active power, bottom: duty cycles given by (25) and (26).
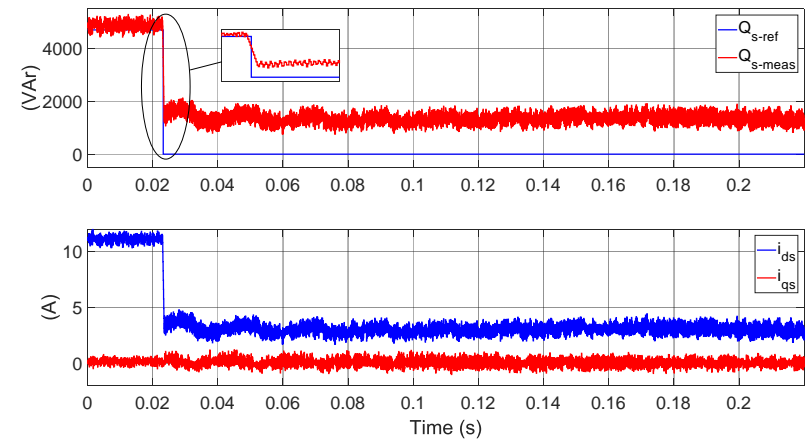

Fig. 14. Experimental results for reactive power step response with constant $L_{m}$ - top: reference and measured reactive power, bottom: measured stator $d$ and $q$-axis currents.

The stator current estimated through (19) is compared with the measured current in Fig. 15. The top plot shows the comparison when the LUT of Fig. 4 is used for $L_{m}$ correction. The bottom plot shows the estimate with constant $L_{m}$. It is evident that the stator current estimation (especially $i_{d s}$ ) is significantly improved with the LUT. Fig. 15 also confirms that with the proposed method, the stator current sensors can very well be excluded without significantly affecting the reactive power control (see also Fig. 11 and 14).

Whereas the reactive power is sensible to saturation effects, the active power control does not suffer from this. The active 

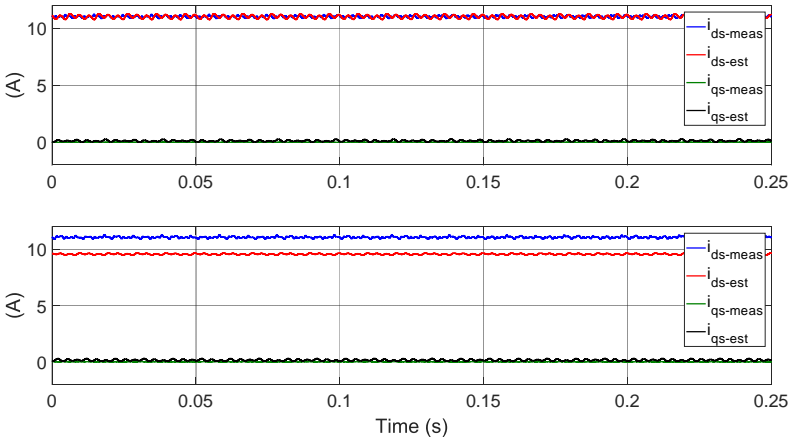

Fig. 15. Experimental results for stator $d$ - and $q$-axis current estimation - top: measured and estimated currents with LUT, bottom: measured and estimated currents with constant $L_{m}$.
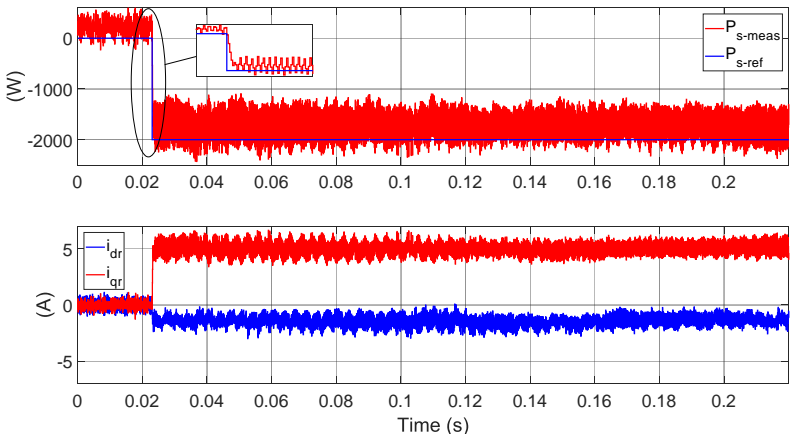

Fig. 16. Experimental results for active power step response with constant $L_{m}$ - top: reference and measured active power, bottom: measured rotor $d$ and $q$-axis currents.

power control results given in Fig. 16 show that with constant $L_{m}$ the estimate of active power has no error and therefore the steady state error is limited (as in Fig. 10).

\section{CONCLUSIONS}

In this paper, a recently developed model predictive control strategy based on optimal voltage vectors is applied for direct power control of a DFIM. The paper has also focused on the magnetic saturation effects that influence the estimation, and therefore the control, of reactive power in the absence of stator current sensors. It has been shown that if the magnetizing characteristic of the machine is known, the stator current sensors can be excluded that will help bring the overall costs down and improve the reliability of the system. A flux observer is designed starting from the measured electrical quantities and, thanks to this flux observer, the need for a phase-locked loop is also eliminated for field orientation. The experimental results have demonstrated that an open-loop reactive power control can be achieved without significant steady-state error in the absence of stator current sensors. In this work, the rotor position is measured through an incremental encoder, however, the implementation of this method for a rotor position sensorless control will be part of future research in this direction.

\section{REFERENCES}

[1] D. Phares, T. Ruegg, and K. Fishel, "Energy-Saving Project of 5500-HP 13-kV Wound Rotor Induction Motor on a Kiln ID Fan Using a Low-
Voltage Slip Power Recovery Drive - A Case Study," IEEE Trans. Ind. Appl., vol. 53, no. 6, pp. 5997-6001, Nov. 2017.

[2] R. Datta and V. Ranganathan, "Direct power control of grid-connected wound rotor induction machine without rotor position sensors," IEEE Trans. Power Electron., vol. 16, no. 3, pp. 390-399, May 2001

[3] D. Sun, X. Wang, H. Nian, and Z. Zhu, "A Sliding-Mode Direct Power Control Strategy for DFIG Under Both Balanced and Unbalanced Grid Conditions Using Extended Active Power," IEEE Trans. Power Electron., vol. 33, no. 2, pp. 1313-1322, 2018.

[4] D. Zhi, L. Xu, and B. W. Williams, "Model-Based Predictive Direct Power Control of Doubly Fed Induction Generators," IEEE Trans. Power Electron., vol. 25, no. 2, pp. 341-351, 2010.

[5] J. Hu, J. Zhu, Y. Zhang, G. Platt, Q. Ma, and D. G. Dorrell, "Predictive direct virtual torque and power control of doubly fed induction generators for fast and smooth grid synchronization and flexible power regulation," IEEE Trans. Power Electron., vol. 28, no. 7, pp. 3182-3194, 2013.

[6] M. E. Zarei, C. V. Nicolás, and J. R. Arribas, "Improved Predictive Direct Power Control of Doubly Fed Induction Generator during Unbalanced Grid Voltage Based on Four Vectors," IEEE J. Emerg. Sel. Topics Power Electron., vol. 5, no. 2, pp. 695-707, 2017.

[7] H. Nian and L. Li, "Direct Power Control of Doubly Fed Induction Generator Without Phase-Locked Loop Under Harmonically Distorted Voltage Conditions," IEEE Trans. Power Electron., vol. 33, no. 7, pp. 5836-5846, Jul. 2018.

[8] J. Hu, J. Zhu, and D. G. Dorrell, "Predictive Direct Power Control of Doubly Fed Induction Generators Under Unbalanced Grid Voltage Conditions for Power Quality Improvement," IEEE Trans. Sustain. Energy, vol. 6, no. 3, pp. 943-950, 2015.

[9] A. J. S. Filho, A. L. Oliveira, L. L. Rodrigues, E. C. M. Costa, and R. V. Jacomini, "A robust finite control set applied to the DFIG power control," IEEE J. Emerg. Sel. Topics Power Electron., pp. 1-1, 2018.

[10] H. T. Nguyen, E.-K. Kim, I.-P. Kim, H. H. Choi, and J.-W. Jung, "Model Predictive Control with Modulated Optimal Vector for a Three-Phase Inverter with an LC filter," IEEE Trans. Power Electron., vol. 33, no. 3, pp. 2690-2703, 2018.

[11] C. Dirscherl and C. M. Hackl, "Model predictive current control with analytical solution and integral error feedback of doubly-fed induction generators with LC filter," in 2017 IEEE Int. Symp. Predictive Control of Elect. Drives and Power Electron. (PRECEDE). IEEE, Sep. 2017 , pp. 25-30.

[12] R. Peña, R. Cárdenas, E. Reyes, J. Clare, and P. Wheeler, "Control of a Doubly Fed Induction Generator via an Indirect Matrix Converter With Changing DC Voltage," IEEE Trans. Ind. Electron., vol. 58, no. 10, pp. 4664-4674, 2011.

[13] N. Amiri, S. M. Madani, T. A. Lipo, and H. A. Zarchi, "An improved direct decoupled power control of doubly fed induction machine without rotor position sensor and with robustness to parameter variation," IEEE Trans. Energy Convers., vol. 27, no. 4, pp. 873-884, 2012.

[14] D. F. Howard, L. Jiaqi, and R. G. Harley, "Short-circuit modeling of DFIGs with uninterrupted control," IEEE J. Emerg. Sel. Topics Power Electron., vol. 2, no. 1, pp. 47-57, 2014.

[15] G. Abad, J. Lopez, M. A. Rodriguez, L. Marroyo, and G. Iwanski, Doubly Fed Induction Machine. New Jersey: Wiley, 2011.

[16] D. Stojic, M. Milinkovic, S. Veinovic, and I. Klasnic, "Improved Stator Flux Estimator for Speed Sensorless Induction Motor Drives," IEEE Trans. Power Electron., vol. 30, no. 4, pp. 2363-2371, Apr. 2015.

[17] G. Pellegrino, R. I. Bojoi, P. Guglielmi, and F. Cupertino, "Accurate Inverter Error Compensation and Related Self-Commissioning Scheme in Sensorless Induction Motor Drives," IEEE Trans. Ind. Appl., vol. 46, no. 5, pp. 1970-1978, Sep. 2010.

[18] J. Rodriguez, M. P. Kazmierkowski, J. R. Espinoza, P. Zanchetta, H. Abu-Rub, H. A. Young, and C. A. Rojas, "State of the Art of Finite Control Set Model Predictive Control in Power Electron." IEEE Trans. Ind. Informat., vol. 9, no. 2, pp. 1003-1016, May 2013.

[19] E. Fuentes, C. A. Silva, and R. M. Kennel, "MPC Implementation of a Quasi-Time-Optimal Speed Control for a PMSM Drive, With Inner Modulated-FS-MPC Torque Control," IEEE Trans. Ind. Electron., vol. 63, no. 6, pp. 3897-3905, Jun. 2016.

[20] C. F. Garcia, C. A. Silva, J. R. Rodriguez, P. Zanchetta, and S. A. Odhano, "Modulated Model Predictive Control with Optimized Overmodulation," IEEE J. Emerg. Sel. Topics Power Electron., pp. 1-1, 2018.

[21] IEEE, "IEEE Standard Test Procedure for Polyphase Induction Motors and Generators," pp. 1-79, 2004. 